\title{
Implementation of the Heinrich Spatial Visualization Test in a Virtual Environment
}

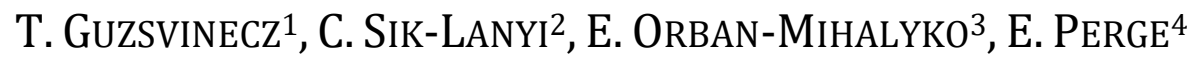 \\ 1University of Pannonia, Faculty of Information Technology, Department of Information Technology and Its \\ Applications, guzsvinecz.tibor@zek.uni-pannon.hu \\ 2University of Pannonia, Faculty of Information Technology, Department of Electrical Engineering and \\ Information Systems, lanyi@almos.uni-pannon.hu \\ 3University of Pannonia, Faculty of Information Technology, Department of Mathematics, orbane@almos.uni- \\ pannon.hu \\ ${ }^{4}$ University of Debrecen, Faculty of Engineering, Department of Basic Technical Studies, perge@eng.unideb.hu
}

Abstract. A virtual environment was developed for PC and Android to be used with a desktop display and the Gear VR, respectively. The goal with it is to measure and enhance the spatial skills of people, because the latter can be achieved by solving simple geometric problems. Originally, this virtual environment consisted only of three such tests, namely the Mental Rotation Test, Mental Cutting Test and Purdue Spatial Visualization Test. Measurements were done in the past with these tests, but now the Heinrich Spatial Visualization Test is also included in the virtual environment. In this paper, its implementation and future measurement plan are presented.

Keywords: cognitive skills, human-computer interaction, mental rotation, spatial ability, virtual environment

\section{Introduction}

With a well-developed spatial ability, a person can understand the relations among objects and space. According to the literature, it can be improved through time and by solving geometric problems [1]. It is extremely important in the modern day, because many jobs require it, and therefore, means to improve spatial skills are included in the curriculum of engineering studies [2]: subjects such as technical representation and descriptive geometry are taught to train the spatial skills of engineering students. According to the literature, due to these (or similar other) courses, their spatial skills are better than that of non-engineering students [3].

Since spatial ability is a cognitive ability and can be improved by solving geometric problems, several tests were developed throughout the years to improve it [4]. Such tests are the Mental Rotation Test (MRT) [5], Mental Cutting Test (MCT) [6], Purdue Spatial Visualization Test (PSVT) [7], and the Heinrich Spatial Visualization Test (HSVT) [8] - just to name a few, since a large number of these tests exist in the literature.

As these tests were developed long ago, their original versions exist on paper, however virtual reality (VR) variants were created of them throughout the years, with the only exception being the HSVT [913]. Since - according to the literature -, when users are immersed inside a virtual environment (VE), 
their learning as well as their spatial skills can be enhanced by stimulating cognitive functions $[14,15]$. The enhancement of spatial skills in VEs was also the conclusion of the authors of this article [16]. However, the number of spatial ability enhancing applications in VEs is scarce, even though the use of VR technologies have effects on cognition [17].

HSVT was developed for selecting engineering students with focus on two various skills: synthesis and decomposition. 48 questions are divided into 6 scales on the original HSVT. With these scales it is possible to include three hierarchical levels of rotations into both synthesis and decomposition versions of HSVT. In Figure 1, an example can be seen for both the synthesis and decomposition versions. These examples also include rotations in case of "X" objects, and these need to be rotated mentally.

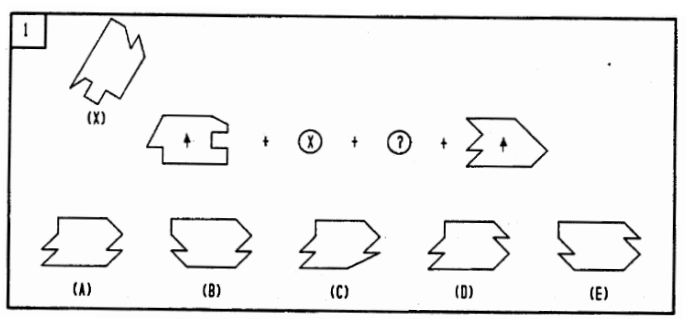

(a)

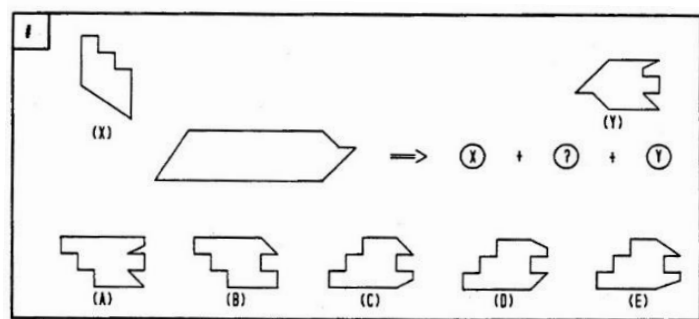

(b)

Figure 1. An HSVT synthesis example with one level of rotation (a) and an HSVT decomposition example with one level of rotation (b) [8].

In case of the synthesis version, objects have to be fitted together mentally. In place of the question mark, an answer should be chosen from the solution set A-E that fits between object X and the end piece when object $\mathrm{X}$ is fitted together with the be-ginning piece. Here, object $\mathrm{A}$ is the correct answer. Contrarily, in case of the decomposition version, an answer should be chosen from the solution set A-E that fits between pieces $\mathrm{X}$ and $\mathrm{Y}$ to construct the object that is on the left of the arrow. It also has to be done mentally. Object $\mathrm{C}$ is the correct answer in this example.

Based on the available literature however, HSVT did not become as popular as the MRT, MCT and PSVT tests among researchers. Some research focused on comparing the results on the tests of Hungarian and Turkish participants: according to Turgut and Nagy-Kondor, Hungarian junior level mathematics teachers scored significantly more on HSVT tests than Turkish ones $[18,19]$.

Besides this, the validity of HSVT was assessed [20, 21]. The analyses present different results among males and females. This is also true in case of other test types [22-24], including HSVT [25]. However, by using head-mounted displays (HMDs) in a VE, the results of females on the spatial ability tests can be improved, making them similar to that of males. It also makes the results of left-handed people similar to right-handed ones [16]. The authors are interested whether a similar phenomenon would occur in case of HSVT tests in VEs, therefore it was implemented in a VE. This implementation is detailed in this paper.

Thus, the structure of this article is the following: the materials and methods are presented in section 1, while discussion regarding the previous results and future measurement plan are shown in section 2 . Lastly, a short conclusion - a summary - can be seen in section 3 . 


\section{Materials and methods}

This section is split into three subsections. The development of the application and the implementation of HSVT are detailed in the first. The virtual environment is presented in the second, while the measurement plan is shown in the third.

\subsection{Implementation of the HSVT tests in a virtual environment}

A spatial ability measuring VR application was developed in 2019 using the Unity game engine [26]. Originally, three test types were implemented: the MRT, MCT and PSVT. Each test type consists of 10 questions in the application and the 3D models were based on their paper-based counterparts. On the upper side of the screen, the original model was shown, while possible answers could be found on the lower part of the screen. The participants had to select the correct answers. In case of the desktop display version, interaction occurs with the keyboard and/or mouse, while in case of the Gear VR version, it occurs with its touchpad.

Still in 2019, the spatial skills of two groups of students were measured: one group consisted of 240 engineering students who tested with a desktop display and the other of 61 students of various fields who tested with the Gear VR head-mounted display device. Their results were evaluated [16, 27, 28]. A post-test was also conducted at the end of the same semester, and the spatial skills of another group of 125 engineering students were measured in 2020, but they were not evaluated yet. Further testing was put on hold due to the COVID-19 pandemic as it required personal contact.

In 2021 the previously developed VE was extended because the HSVT test were implemented in it. After gathering HSVT questions and possible answers, 3D models were created of them: the application called Inkscape was used to create SVG files of JPG which served as a basis for the models. Afterward, 3D models were created from the SVG files in Blender 2.82. Lastly, the VE's source code was modified to include the HSVT test mode with these new 3D models.

\subsection{The virtual environment}

It is possible to change the display parameters of the application before starting the test, although this feature can be set to automatic. The display parameters are the following: virtual camera type, its field of view, its rotation, the contrast ratio and whether there are shadows in the scene. This allows for complex analysis of the results.

In Figure 2 the original and the authors' 3D versions of HSVT questions can be seen. The latter is illustrated in multiple subfigures because two virtual camera types can be observed in them. The camera looks at the center of the screen. Since a perspective camera is similar to the human eye, 3D objects can be observed in the virtual environment. This means that all objects can be seen in a slightly different angle. Contrarily, the orthographic camera uses orthogonal projection, resulting in objects that look differently. In case of HSVT, these objects look like they are 2D ones, but in actuality, these objects still have depth. Besides these parameters in the subfigures of Figure 2, the shadows are turned off in the virtual environment. 


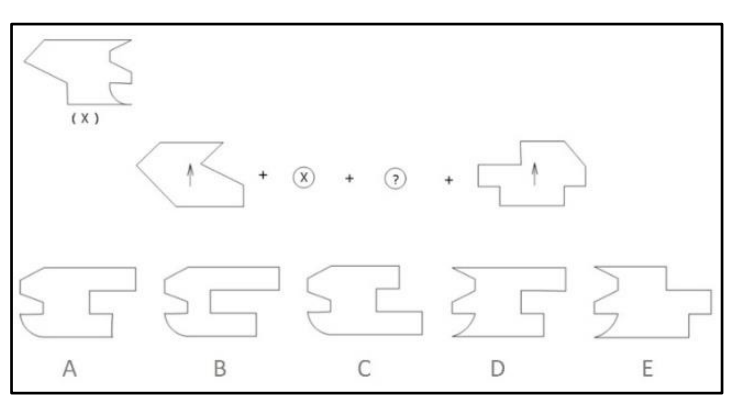

(a)

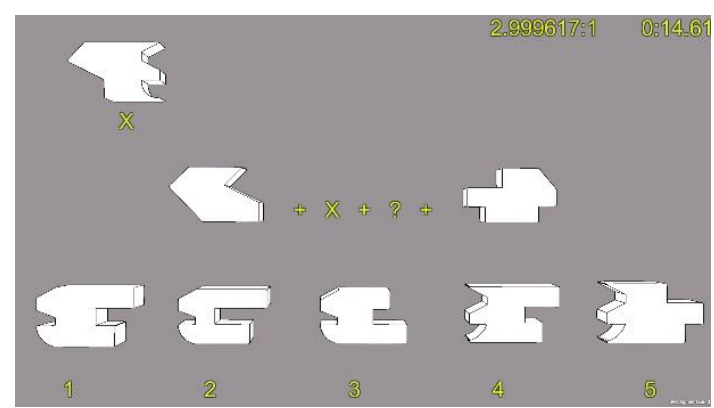

(b)

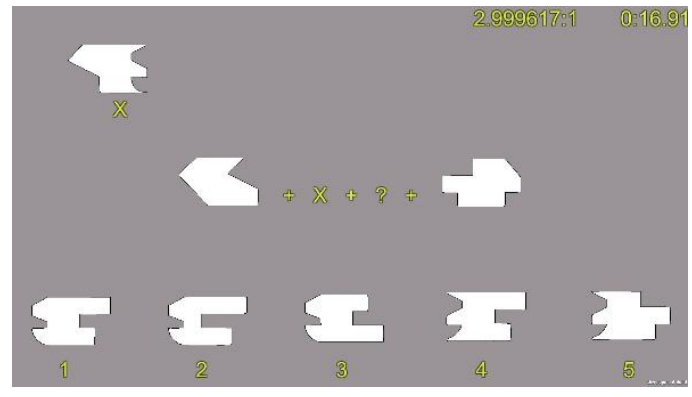

(c)

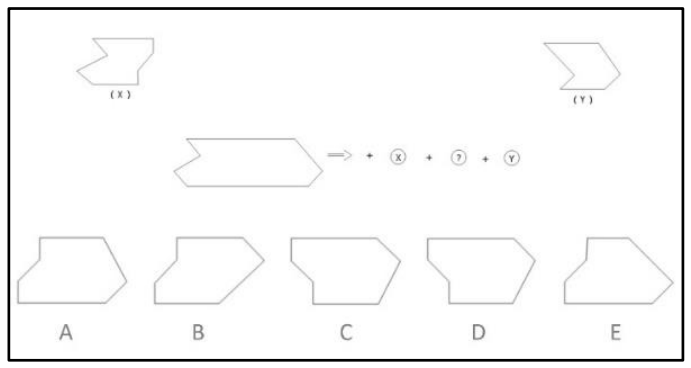

(d)

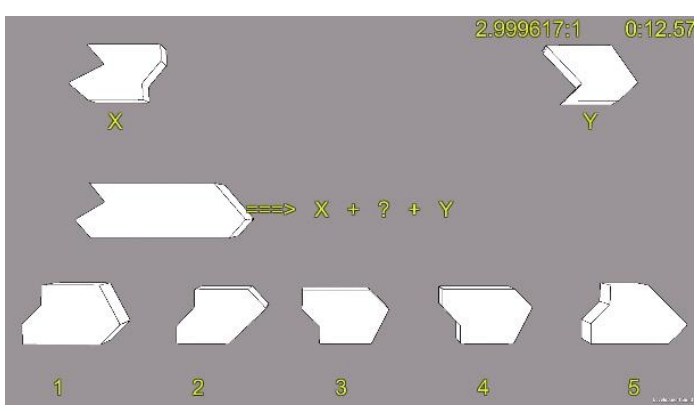

(e)

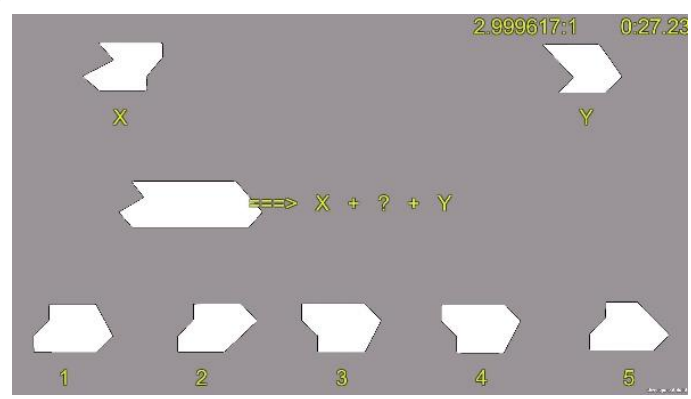

(f)

Figure 2. Synthesis version of HSVT with original 2D objects (a), synthesis version of HSVT with 3D objects in the VE using a perspective camera (b), synthesis version of HSVT with $3 D$ objects in the VE using an orthographic camera (c), decomposition version of HSVT with original 2D objects (d), decomposition version of HSVT with 3D objects in the VE using a perspective camera (e), and decomposition version of HSVT with 3D objects in the VE using an orthographic camera $(f)$.

In the VE there are 32 HSVT problems implemented. Out of them, 16 are synthesis problems and 16 are decomposition problems. Similarly to the paper-based tests, three levels of rotation are implemented as well. These are randomized in the virtual environment, and they are the following: 1) no objects are rotated; 2) only X objects are rotated; 3 ) X and A-E (meaning 1-5) objects are rotated. These levels can very between different questions. 
Naturally, as this is a type of mental rotation tests, the objects have to be rotated mentally. The virtual camera (or the user) is placed in front of the objects. It is not permitted by the virtual environment to walk around the objects. This fact makes the procedure similar to the paper-based HSVT test.

\subsection{Measurement plan}

Since face-to-face education is allowed at universities in Hungary at the moment, the measurements will start in a few weeks with using HSVT in the VE. Similarly to the authors' previous measurements, it will include two display devices: an LG 20M37A (19.5") desktop display and the Gear VR HMD device. As before, various groups of people will test with each version. The desktop display version will be used by the University of Debrecen, while the Gear VR version will be used by the University of Pannonia. It is also planned to conduct a pre-test and post-test of HSVT in the same semester at the University of Debrecen. First, the students have to solve 16 synthesis problems. After that, they can rest if they want to. Afterward, 16 decomposition problems have to be solved. The sequence of each group of problems is random. The level of rotation per question is random as well. Naturally, the authors will ask for consent before each measurement.

It should be mentioned that since the authors want investigate the effects of the VE's parameters as well, the virtual camera, its field of view, its rotation, contrast ratio and whether there are shadows in the scene are randomized before starting a 16-problem sequence. Naturally, this can only be investigated when a large number of students complete the tests.

When the measurements are completed, the statistical program package $\mathrm{R}$ will be used to evaluate the data. Similarly, the results achieved using both devices will be investigated and compared to each other.

\section{Discussion}

As the HSVT is included now in the VE, it is possible to expand on previous research of the authors. It can be investigated whether similar effects occur in case of HSVT as in the MRT, MCT, and PSVT test types. As was mentioned, according to the results on the paper-based tests, the spatial skills of males are better than that of females, as well as right-handed people performed better on them than their lefthanded counterparts. When an HMD is used, significant improvements can be found between two PSVT tests.

Based on the authors' previous research [16], males outperform females, and right-handed people also outperform left-handed ones on the spatial ability tests when a desktop display device is used. If an HMD is used, significant changes occur between the results: the significant difference disappears between the results of males and females as well as between right-handed and left-handed people. The ratio of correct answers is also better with the Gear VR. It is also known that the Gear VR's use increases the time it took to complete the tests, and the effect is the largest in case of the MRT test type [28].

The spatial skills of users can be enhanced simply by a VE that is carefully designed. Also based on previous research [27], to enhance spatial skills of users, the optimal VE preference is the following: a perspective type of virtual camera that has a rotation of $-45^{\circ}$, or $0^{\circ}, 45^{\circ}$, a contrast ratio of $1.5: 1$ or $3: 1$ 
between the background and the foreground objects; as well as an HMD. This means that these factors increase the probability of correct answers.

Therefore, based on the previous results, the following research questions (RQs) are formulated regarding HSVT tests in the VE: will the Gear VR's use significantly increase HSVT test completion times as well as the ratio of correct answers of females or left-handed people? Will the parameters of the VE increase the probability of correct answers received on the HSVT tests? Will there be a significant difference between an HSVT pre-test and a post-test?

\section{Conclusions}

In this paper the implementation of the HSVT test type into an existing VE was detailed. Implementation consisted of mainly transforming 2D drawings of HSVT questions and answers into 3D objects. Afterward, Unity game engine was used to place them into the existing VE. This VE can be used on two platforms: Android (using the Gear VR) and PC (using a desktop display). Lastly, based on previous studies of the authors, a measurement plan was set up.

Since no such project was found in the literature, it can be stated that the existence of HSVT tests in a VE using a desktop display and an HMD is new. It would be interesting to see how VR technology affects the results of participants who took these new VR versions of HSVT tests. Hopefully, the measurements and investigation can begin soon.

\section{Acknowledgments}

The authors would like to thank Professor Ayres D'Costa for his help regarding HSVT tests.

\section{References}

[1] Miller, C.L. and Bertoline, G.R. (1991). 'Spatial Visualization Research and Theories: Their Importance in the Development of an Engineering and Technical Design Graphics Curriculum Model', Engineering Design Graphics Journal, 55(3), pp. 5-14.

[2] Khine, M.S. (2016) 'Spatial Cognition: Key to STEM Success', Visual-spatial Ability in STEM Education, pp. 3-8. doi: 10.1007/978-3-319-44385-0_1

[3] Peters, M., Chisholm, P. and Laeng, B. (1995) 'Spatial Ability, Student Gender, and Academic Performance', Journal of Engineering Education, 84(1), pp. 69-73. doi: 10.1002/j.21689830.1995.tb00148.x

[4] Nagy-Kondor, R. (2017) 'Spatial ability: measurement and development', In Visual-spatial Ability in STEM education, pp. 35-58. Springer, Cham. doi: 10.1007/978-3-319-44385-0_3

[5] Ault, H.K. and John, S. (2010) 'Assessing and Enhancing Visualization Skills of Engineering Students in Africa: A Comparative Study', The Engineering Design Graphics Journal, 74(2), pp. 12-20.

[6] College Entrance Examination Board (CEEB) (1939) 'Special aptitude test in spatial relations', developed by the college entrance examination board. 
[7] Branoff, T. and Connolly, P.E. (1999) 'The Addition Of Coordinate Axes To The Purdue Spatial Visualization Test Visualization Of Rotations: A Study At Two Universities', 1999 Annual Conference, pp. 4.506.1-4.506.9.

[8] Heinrich, V. (1988) 'A Spatial Visualization Test for Selecting Engineering Students'. (Master's Thesis)

[9] Gómez-Tone, H.C., Martin-Gutierrez, J., Valencia Anci, L. and Mora Luis, C.E. (2020) 'International Comparative Pilot Study of Spatial Skill Development in Engineering Students through Autonomous Augmented Reality-Based Training', Symmetry, 12(9), pp. 1401. doi: 10.3390/sym12091401

[10] Molina-Carmona, R., Pertegal-Felices, M., Jimeno-Morenilla, A. and Mora-Mora, H. (2018) 'Virtual Reality Learning Activities for Multimedia Students to Enhance Spatial Ability', Sustainability, 10(4), pp. 1074. doi: 10.3390/su10041074

[11] Rizzo, A.A., Buckwalter, J.G., Neumann, U., Kesselman, C., Thiébaux, M., Larson, P. and van Rooyen, A. (1998) 'The Virtual Reality Mental Rotation Spatial Skills Project', CyberPsychology \& Behavior, 1(2), pp. 113-119. doi: 10.1089/cpb.1998.1.113

[12] Tóth, R., Zichar, M. and Hoffmann, M. (2020) 'Improving and Measuring Spatial Skills with Augmented Reality and Gamification', Advances in Intelligent Systems and Computing, pp. 755-764. doi: 10.1007/978-3-030-63403-2_68

[13] Tóth, R., Zichar, M. and Hoffmann, M. (2020) 'Gamified Mental Cutting Test for enhancing spatial skills', 2020 11th IEEE International Conference on Cognitive Infocommunications (CogInfoCom), pp. 299-304. doi: 10.1109/CogInfoCom50765.2020.9237888

[14] Korečko, Š., Hudák, M., Sobota, B., Marko, M., Cimrová, B., Farkaš, I. and Rosipal, R. (2018) 'Assessment and training of visuospatial cognitive functions in virtual reality: proposal and perspective', 2018 9th IEEE International Conference on Cognitive Infocommunications (CogInfoCom), pp. 39-44. doi: 10.1109/CogInfoCom.2018.8639958

[15] Kövecses-Gősi, V. (2018) 'Cooperative Learning in VR Environment', Acta Polytechnica Hungarica, 15(3), pp. 205-224. doi: 10.12700/APH.15.3.2018.3.12

[16] Guzsvinecz, T., Orbán-Mihálykó, É., Perge, E. and Sik-Lányi, C. (2020) 'Analyzing the spatial skills of university students with a Virtual Reality application using a desktop display and the Gear VR', Acta Polytechnica Hungarica, 17(2), pp. 205-224. doi: 10.12700/APH.17.2.2020.2.3

[17] Huang, C.L., Luo, Y.F., Yang, S.C., Lu, C.M. and Chen, A.-S. (2019) 'Influence of Students' Learning Style, Sense of Presence, and Cognitive Load on Learning Outcomes in an Immersive Virtual Reality Learning Environment', Journal of Educational Computing Research, 58(3), pp. 596-615. doi: $10.1177 / 0735633119867422$

[18] Turgut, M. and Nagy-Kondor, R. (2013) 'Spatial visualization skills of Hungarian and Turkish prospective mathematics teachers', Jornal Internacional de Estudos em Educação Matemática, 6(1), pp. 168-183.

[19] Nagy-Kondor, R. (2014) 'Importance of spatial visualization skills in Hungary and Turkey: Comparative Studies', Annales Mathematicae et Informaticae, 43, pp. 171-181. 
[20] Chen, K.H. (1995) 'Validity studies of the Heinrich spatial visualization test'. (PhD Thesis)

[21] Tang, M. (2006) 'Gender differences in relationship between background experiences and three levels of spatial ability'. (PhD Thesis)

[22] Burnett, S.A., Lane, D.M. and Dratt, L.M. (1982) 'Spatial ability and handedness', Intelligence, 6(1), pp. 57-68. doi: 10.1016/0160-2896(82)90020-4

[23] McKeever, W.F. (1986) 'The Influences of Handedness, Sex, Familial Sinistrality and Androgyny on Language Laterality, Verbal Ability, and Spatial Ability',Cortex, 22(4), pp. 521-537. doi: 10.1016/S0010-9452(86)80013-2

[24] Nazareth, A., Herrera, A., Pruden, S.M. (2013) 'Explaining sex differences in mental rotation: role of spatial activity experience', Cognitive processing, 14(2), pp. 201-204. doi: 10.1007/s10339-0130542-8

[25] Nagy-Kondor, R. (2016) 'Gender differences in spatial visualization skills of engineering students', Annales Mathematicae et Informaticae, 46, pp. 265-276.

[26] Guzsvinecz, T., Szeles, M., Perge, E. and Sik-Lanyi, C. (2019) 'Preparing spatial ability tests in a virtual reality application', 2019 10th IEEE International Conference on Cognitive Infocommunications (CogInfoCom), pp. 363-368. doi: 10.1109/CogInfoCom47531.2019.9089919

[27] Guzsvinecz, T., Sik-Lanyi, C., Orban-Mihalyko, E. and Perge, E. (2020) 'The Influence of Display Parameters and Display Devices over Spatial Ability Test Answers in Virtual Reality Environments', Applied Sciences, 10(2), pp. 526. doi: 10.3390/app10020526

[28] Guzsvinecz, T., Orbán-Mihálykó, É., Sik-Lányi, C. and Perge, E. (2021) 'Investigation of spatial ability test completion times in virtual reality using a desktop display and the Gear VR', Virtual Reality. doi: 10.1007/s10055-021-00509-2 